\title{
Obstetricians on the Coronavirus Disease 2019 (COVID-19) Front Lines and the Confusing World of Personal Protective Equipment
}

\author{
Denise J.Jamieson, MD, MPH, James P. Steinberg, MD, Richard A. Martinello, MD, Trish M. Perl, MD, MSc, \\ and Sonja A. Rasmussen, $M D, M S$
}

\begin{abstract}
As health care systems struggle to maintain adequate supplies of personal protective equipment, there is confusion and anxiety among obstetricians and others about how to best protect themselves, their coworkers, and their patients. Although use of personal protective equipment is a critical strategy to protect health care personnel from coronavirus disease 2019 (COVID-19), other strategies also need to be implemented on labor and delivery units to reduce the risk of health care-
\end{abstract}

From the Departments of Gynecology and Obstetrics and Medicine, Emory University School of Medicine, Atlanta, Georgia; the Departments of Medicine and Pediatrics, Yale School of Medicine, and the Department of Infection Prevention, Yale New Haven Health, New Haven, Connecticut; the University of Texas Southwestern Medical Center, Dallas, Texas; and the Departments of Pediatrics and Epidemiology, University of Florida College of Medicine \& College of Public Health and Health Professions, Gainesville, Florida.

Each author has confirmed compliance with the journal's requirements for authorship.

Corresponding author: Denise J. Jamieson, MD, MPH, Department of Gynecology and Obstetrics, Emory University School of Medicine, Woodruff Memorial Research Building, Atlanta, GA; email: djamieson@emory.edu.

\section{Financial Disclosure}

Trish M. Perl reports receiving money paid to her institution from BARDA funding for ResPECT study finding. Sonja A. Rasmussen reports that she worked as a litigation consultant on behalf of Hoffmann-La Roche for a product liability claim regarding an alleged birth defect. She serves on an advisory committees providing birth defects expertise for the Teva Pregnancy Registry Advisory Committee. She has not received payment for this work to date, but will likely receive payment in the future. She serves on an advisory committee providing birth defects expertise for the Solriamfetol Pregnancy Registry Advisory Committee. She has not received payment for this work to date, but will likely receive payment in the future. She serves on a Steering Committee for the Gilenya Pregnancy Registry. She has received payment for this work. She has also been serving as a consultant to two companies (these are tech companies - they do not make respiratory protective devices or pharmaceuticals) regarding how to keep their employees safe from COVID-19. She has not received payment for this work to date, but may receive payment in the future. The other authors did not report any potential conflicts of interest.

(C) 2020 by the American College of Obstetricians and Gynecologists. Published by Wolters Kluwer Health, Inc. All rights reserved.

ISSN: 0029-7844/20 associated transmission, including screening of all pregnant women who present for care (case identification), placing a mask on and rapidly isolating ill pregnant women, and minimizing the number of personnel who enter the room of an ill patient (physical distancing). Although the mechanism of transmission of COVID-19 is not known with certainty, current evidence suggests that COVID-19 is transmitted primarily through respiratory droplets. Therefore, strict adherence to hand hygiene and consistent use of recommended personal protective equipment are cornerstones for reducing transmission. In addition, it is critical that health care professionals receive training on and practice correct donning (putting on) and doffing (removing) of personal protective equipment and avoid touching their faces as well as their facial protection to minimize self-contamination.

(Obstet Gynecol 2020;135:1257-63)

DOI: 10.1097/AOG.0000000000003919

A s coronavirus disease 2019 (COVID-19) sweeps A across the United States, health care settings are struggling to protect their health care workers as supplies of personal protective equipment dwindle during the unprecedented onslaught of COVID-19 cases. Although health care systems are increasingly postponing all nonurgent clinical care, including surgeries, obstetricians do not have that option; pandemic or not, pregnant women continue to deliver newborns. Although most pregnant women presenting for delivery are not likely to have COVID-19 infection, some will, placing obstetricians on the front line in the fight against COVID-19. This means that obstetricians need to determine how to minimize their risk of contracting COVID-19 while continuing to provide highquality care to the women that they serve. These efforts are challenged by shortages that are occurring or 
anticipated in supplies of personal protective equipment, including N95 respirators, surgical masks, gowns, gloves, face shields, and goggles. Furthermore, given the uncertainties on how this disease is transmitted, health care workers, including obstetricians, are understandably confused and anxious about how COVID-19 is spread and how to best protect themselves as health care workers, which ultimately protects the patients they serve. The goal of this article is to review what is known about personal protective equipment in the context of transmission of COVID-19, recognizing that this is a rapidly evolving topic.

\section{WHAT IS KNOWN ABOUT COVID-19 AND ITS TRANSMISSION}

Coronavirus 2019 is caused by a novel coronavirus called severe acute respiratory syndrome coronavirus 2 (SARS-CoV-2), because its genetic sequence is approximately $80 \%$ similar to the virus that caused severe acute respiratory syndrome (SARS), which is now called $S A R S-C o V-1$. This virus was first recognized in China in December of 2019 and has rapidly spread throughout the world. The most common manifestations include fever, cough, myalgia, extreme fatigue, and shortness of breath, with less commonly reported symptoms including sore throat, headache, anosmia, dysgeusia, diarrhea, and nausea. Data from China suggest that $81 \%$ of patients with confirmed cases have illness that is mild (not requiring hospitalization), 14\% have severe illness (generally characterized by pneumonia and typically requiring hospitalization), and 5\% have critical illness often requiring care in an intensive care unit. Persons at highest risk are those older than 65 years of age and those with underlying health conditions (eg, cardiovascular conditions, diabetes, hypertension, chronic respiratory disease). ${ }^{1,2}$ Although estimates of case fatality rates have varied widely, a recent study using individual case data from China estimated both the case fatality rate, which is the proportion of clinically recognized cases that will eventually lead to death, and the infection fatality rate, which is the proportion of all infections that will eventually lead to death, as $1.38 \%$ and $0.66 \%$, respectively. ${ }^{3}$ The true case fatality rate and the infection fatality rate will not be known until serosurveys allow for a more precise measurement of those with undiagnosed infections and may vary from region to region based on availability of health care resources. The COVID-19 pandemic is evolving rapidly; although there is a great deal we do not know, we continue to learn more daily.
As with other issues related to COVID-19, much remains to be learned about SARS-CoV-2 transmission. Based on available data, evidence supports that transmission is similar to that of influenza, SARS, and Middle East respiratory syndrome-primarily personto-person through respiratory droplets that are produced when a person coughs, sneezes, or talks among close contacts. Large droplets typically do not travel more than 6 feet; thus, close contact is defined as less than 6 feet from a person with COVID-19 infection. Droplets that land in the mouths, noses, or eyes or possibly are inhaled into the lungs of people in close contact can cause infection. However, under some circumstances, droplets may travel more than 6 feet, depending on various factors such as expiratory effort, viscosity of the respiratory secretions, and air currents in the area. ${ }^{4}$ Furthermore, recent work has suggested that exhalations, sneezes, and coughs may create turbulent gas clouds that may be able to travel longer distances. ${ }^{5}$ Infection may also occur when a person touches a surface contaminated with the infectious secretions and respiratory droplets from a person with infection. ${ }^{6}$ Although SARS-CoV-2 has been detected in stool by polymerase chain reaction testing, it remains unknown whether infectious virus may be shed in stool or whether stool may play a role in the transmission of SARS-CoV-2. ${ }^{7}$

The contribution of infectious aerosols (small respirable particles) to the transmission of COVID19 is currently unknown. Some of this uncertainty about the role of airborne transmission of SARS-CoV2 parallels the uncertainty regarding influenza transmission. Although airborne transmission of influenza can be demonstrated in experimental models and selected circumstances, such as airplanes with disabled ventilation systems, ${ }^{8}$ the contribution of airborne spread to influenza transmission is thought to be small. Furthermore, the relevance of experimental models to viral transmission in clinical settings is unclear. In an artificial experiment that generated SARS-CoV-2 aerosols in a laboratory setting without hospital-level ventilation systems, virus remained viable in aerosols for as long as 3 hours. ${ }^{9}$ However, in an analysis of air samples near a patient with a high viral load of SARS-CoV-2, virus was not identified in eight air samples after a patient was instructed to breath normally, breathe deeply, speak, and cough continuously; these specimens were collected at a distance of $10 \mathrm{~cm}$ from the patient's chin, with or without wearing a surgical mask. ${ }^{10}$ During certain medical procedures involving the respiratory tract, such as noninvasive ventilation, cardiopulmonary resuscitation, and endotracheal intubation, respiratory aerosols can be 
generated. ${ }^{11,12}$ However, other studies have questioned whether significant aerosols are generated from some of these procedures. ${ }^{13}$

Although most COVID-19 infections are related to exposure to persons with symptomatic disease, two reports of viral shedding and likely transmission by presymptomatic (period before developing overt COVID-19 infection) or asymptomatic persons raise concern that, in areas with active COVID-19 transmission, all patients should be considered as potential sources. One report describes seven clusters of transmission in Singapore where transmission likely occurred before source patients became symptomatic. This asymptomatic transmission accounted for $6.4 \%$ of known COVID-19 transmission locally. ${ }^{14}$ In another report from an outbreak in a skilled nursing facility in the United States, about half of residents with detectable virus were asymptomatic or presymptomatic at the time of sampling; viral levels measured by polymerase chain reaction cycle time were similar for those with and without symptoms. ${ }^{15}$ Although these findings may not be generalizable to the obstetric population, they demonstrate the potential for unrecognized viral shedding in areas of high disease prevalence. Among 215 women admitted for delivery at two hospitals in New York City, 29 of the $33(88 \%)$ who tested positive for SARS-CoV-2 were asymptomatic at presentation (Sutton D, Fuchs K, D'Alton M, Goffman D. Universal screening for SARSCoV-2 in women admitted for delivery [letter]. New Engl J Med 2020 Apr 13 [Epub ahead of print].)

\section{RECOMMENDATIONS FOR OBSTETRIC HEALTH CARE SETTINGS TO REDUCE HEALTH CARE PERSONNEL EXPOSURE TO COVID-19}

Although the use of personal protective equipment is a critical strategy to protect health care workers, other strategies also need to be implemented. Case finding is one such strategy and a pillar to preventing exposure in health care settings. Before entering an ambulatory care setting, pregnant patients need to be screened for possible symptoms of COVID-19 or exposures to patients with known or suspected COVID-19. This can be done by telephone when outpatient appointments are scheduled. Patients with symptoms or significant exposures should be assessed to determine whether an in-person appointment is necessary or whether the patient can be seen through telemedicine and managed at home. ${ }^{16}$ If an outpatient appointment is necessary, a facemask should be placed on any patient with respiratory symptoms immediately on presentation (known as source control), and she should be quickly isolated in an examination room with the door closed. If the prevalence of
COVID-19 in the community is high, placing a mask on all patients should be considered to minimize potential transmission from presymptomatic or asymptomatic patients with COVID-19 infection who could be shedding virus. Triage areas should be separate, well-ventilated areas, and barriers should ensure that patients are separated (eg, plexiglass barriers) from staff during the screening process. Patients in triage areas should sit at least 6 feet apart, which commonly requires rearranging the seating. Ample hand hygiene dispensers should be placed in triage areas, waiting rooms, and patient care areas. The number of personnel entering the room of a patient with suspected or confirmed COVID-19 infection should be minimized. This may be accomplished by having physicians perform some aspects of patient care that may normally be performed by nursing staff (eg, vital signs). Some tasks, such as visits with dieticians, can be virtual. Hand hygiene is critically important for preventing nosocomial transmission of COVID-19, particularly with the demonstration of persistence of virus on surfaces from several hours up to 3 days depending on the surface material. ${ }^{10}$ Furthermore, frequent cleaning of surfaces and rooms should be undertaken, with high-touch areas such as door knobs, faucets, and chair arms being wiped with an appropriate disinfectant between patients.

Use of personal protective equipment is a fundamental strategy for protection of health care workers. Current recommendations from the Centers for Disease Control and Prevention (CDC) for care of persons with known or suspected COVID-19 infection include an N95 respirator, if available (or facemask if a respirator is not available), eye protection, gown, and gloves. ${ }^{17}$ These recommendations are based on a systematic review that demonstrated that the odds ratio (OR) of acquiring a respiratory virus infection is 0.32 (95\% CI 0.26-0.39) if wearing a facemask, $0.17(95 \%$ CI 0.07-0.43) if wearing an N95 respirator, $0.32(95 \%$ CI $0.23-0.45)$ if wearing gloves, and 0.33 (95\% CI 0.24-0.45) if wearing a gown. If all interventions are included, the $\mathrm{OR}$ of developing a respiratory viral infection is 0.09 (95\% CI 0.02-0.35). The OR of acquiring a respiratory viral infection with the use of eye protection is $0.10(95 \%$ CI $0.05-0.17) .{ }^{18}$

An N95 respirator is a personal protective device that covers the nose and mouth, fits tightly, and reduces the wearer's risk of inhaling airborne particles. These respirators are designed to prevent the wearer from diseases known or suspected to be transmitted by airborne droplet nuclei, including measles, varicella, and Mycobacterium tuberculosis. Unlike respiratory viruses that are primarily spread by droplets, 
these specific microorganisms can be widely dispersed by air currents and may be inhaled by a person in the same room or over a long distance from the patient, depending on factors such as temperature and ventilation. ${ }^{19}$ For settings in which airborne transmission is the primary transmission mechanism, there are three respirator options. An N95 respirator filters out at least $95 \%$ of airborne particles sized 0.3 micrometers in diameter, although, in practice up to $10 \%$ of N95 respirator users exposed to aerosolized influenza had breakthrough leakage. ${ }^{20}$ Another type of respirator is a powered air-purifying respirator, which uses highefficiency particulate air filters. These respirators are reusable and must be cleaned and disinfected after each use. Filters should be replaced according the manufacturer's recommendations. The National Institute for Occupational Safety and Health has cautioned against use of powered air-purifying respirators in the operating room because of concerns that unfiltered exhaled air may contaminate the sterile field and the absence of scientific evidence to support use. However, a preliminary experimental study using two types of powered air-purifying respirators found no contamination of the surgical field. Although these findings are reassuring, further study is needed. ${ }^{21}$ Cartridge air purifying respirators are another option; depending on the filter cartridge chosen, they can provide a similar level of respiratory protection to that provided by an N95 respirator and can be reused. These respirators generally have not been designed for use in the health care settings; communication with patients may be difficult during use, and there are no manufacturer instructions for decontamination.

A facemask is a standard FDA-cleared medical mask that may or may not have a plastic face shield attached; these are the standard masks used on labor and delivery units. Surgical masks prevent transmission of viruses transmitted by large droplets, a common method for prevention of transmission of respiratory viral illnesses. ${ }^{19}$ Importantly, whether a medical mask or respirator, the operator must wear facial protection correctly and use eye protection to assure that all mucous membranes are covered.

\section{ARE N95 MASKS SUPERIOR TO SURGICAL MASKS IN PREVENTING NOSOCOMIAL COVID-19 TRANSMISSION?}

When caring for patients with suspected or confirmed COVID-19 infection, CDC guidance states that facemasks are an acceptable alternative to N95 masks when the supply of N95 masks is insufficient, except when aerosol-generating procedures are performed. ${ }^{17}$ Although the CDC guidance implies that N95 masks are superior to facemasks, there are some recent, reassuring data about the effectiveness of facemasks in illnesses transmitted by respiratory droplets.

Previous studies have provided mixed results, and the majority of studies assessing respiratory protection against viruses have focused on influenza. A noninferiority randomized trial of 446 nurses concluded that surgical masks compared with N95 masks resulted in noninferior rates of laboratory-confirmed influenza. However, this study was halted prematurely owing to the onset of the $2009 \mathrm{H} 1 \mathrm{~N} 1$ pandemic and changes in the health system's recommended personal protective equipment use..$^{22} \mathrm{By}$ contrast, the authors of two other randomized trials, ${ }^{23,24}$ as well as a pooled analysis of the two studies, ${ }^{25}$ concluded that N95 masks may be more effective than surgical masks. Although the N95 group had lower rates of clinical respiratory illness, influenza-like illness, laboratory-confirmed respiratory infection, and laboratory-confirmed influenza compared with the surgical mask group, these differences were not statistically significant in the intent-to-treat analysis. ${ }^{25} \mathrm{~A}$ recent 4 -year cluster randomized trial compared the effect of N95 respirators with that of facemasks among 2,862 health care personnel. The study found no significant difference in the incidence of laboratory-confirmed influenza for those wearing N95 respirators compared with those wearing face masks. ${ }^{26}$ A recent Cochrane Systematic Review found that N95 respirators were not significantly different than surgical masks in preventing respiratory virus acquisition but were more expensive, uncomfortable, and irritating to skin. ${ }^{18}$ Using polymerase chain reaction testing, a recent case report found no transmission of SARS-CoV-2 to 41 health care workers who had more than 10 minutes of exposure at less than $2 \mathrm{~m}$ from a patient undergoing multiple aerosolizing procedures; $85 \%$ of these health care workers wore surgical masks. ${ }^{27}$ Although this report is reassuring, it is limited by being an isolated case report.

\section{ARE VAGINAL OR CESAREAN DELIVERIES AEROSOL-GENERATING PROCEDURES?}

There has been a great deal of discussion and debate in obstetric circles about what does and does not constitute an aerosolizing procedure. Because the CDC guidance states that N95 masks are important when aerosol-generating procedures are performed, ${ }^{17}$ it is important to be able to identify procedures on the labor and delivery unit that have a high likelihood of producing aerosols. Intubation for general anesthesia has been shown to produce aerosols and may increase the risk of transmission to the person performing the intubation. By contrast, cesarean deliveries under 
neuraxial anesthesia (ie, spinal or epidural) are unlikely to produce aerosols.

There has been speculation that the labored breathing and expulsive efforts of pushing in the second stage of labor may generate aerosols. Although the risks of aerosolization during vaginal delivery have not been studied, most aerosolizing procedures that have been identified as high risk (eg, intubation, bronchoscopy) involve direct manipulation of the respiratory tract. ${ }^{11,12}$ However, of the role of turbulent gas clouds in COVID-19 transmission is not known. ${ }^{5}$ Given the limitations of the current evidence, it is not possible to definitely state whether or not aerosols are generated during the second stage of labor. However, given what we know to date, it is highly likely that the primary method of transmission of COVID-19 is through respiratory droplets. All women with COVID-19 infection should wear a facemask during their entire hospitalization, including during the second stage of labor (source control) when possible.

\section{IS IT SAFE TO REUSE RESPIRATORS?}

Currently, there are challenges with adequate supplies of personal protective equipment, with some hospitals having shortages of certain types of personal protective equipment and some reporting overall shortages. Problems with the personal protective equipment supply chain in the United States have been described during previous public health emergencies. For example, during the $2009 \mathrm{H} 1 \mathrm{~N} 1$ influenza pandemic, the commercial supply could not keep up with the demand for N95 masks and facemasks. To address shortages, supplies from the U.S. Strategic National Stockpile were released. Since that time, the Strategic National Stockpile has not been replenished to the pre-H1N1 level, and the personal protective equipment supply chain has not substantially improved, ${ }^{28}$ resulting in shortages during the current COVID-19 pandemic. Thus, extended use and limited reuse have been recommended by the $\mathrm{CDC}$ as strategies to conserve personal protective equipment. Extended use refers to wearing the same N95 mask for repeated contact with several patients. Limited reuse involves using the same N95 mask for contact with several patients but removing ("doffing") it between patient encounters. ${ }^{29}$ For pathogens such as tuberculosis, in which transmission from fomites is not a concern, N95 mask reuse has been widely practiced. With COVID-19, the primary infection risk from reuse is self-inoculation if the surface of the N95 mask becomes contaminated. In a study of 10 nurses during two 12-hour shifts, nurses touched their faces or the N95 mask more than 20 times per 12-hour shift. ${ }^{30}$ Therefore, if extended use or reuse of N95 masks is practiced, it is critical that health care professionals practice correct donning and doffing, practice good hand hygiene, and avoid touching the N95 mask or their faces during use. Although it is unknown whether SARS-CoV-2 may contaminate the filtering material of respirators, influenza virus was able to be recovered from N95 respirators experimentally exposed to aerosols containing influenza. ${ }^{31}$

Given the possibility of exhausting the supply of N95 respirators during the COVID-19 pandemic, many health care organizations have resorted to reuse of N95 masks beyond the CDC's limited recommendation, with continued use of respirators until they become soiled or lose integrity. Novel cleaning regimens, including the use of UV light, vaporized hydrogen peroxide, or other methods, have been suggested. ${ }^{32-35}$

\section{DO CLOTH MASKS PROVIDE GOOD PROTECTION?}

With current mask shortages, members of the public have been offering to sew cloth masks. A clusterrandomized trial of medical and cloth masks found a significantly higher rate of influenza-like illness among health care workers in the cloth mask arm compared with the medical mask arm. ${ }^{36}$ In addition, cloth masks have limited ability to protect the wearer against the penetration of fluids through the mask after a splash. Therefore, hospital systems should be cautious about using cloth masks for direct patient care activity with patients under investigation for or with confirmed COVID-19 infection. Cloth masks are likely effective in capturing large droplets and keeping the wearer from being a source of transmission. Owing to evidence that people with COVID-19 infection who do not have symptoms can transmit the virus to others, ${ }^{37}$ the CDC has recently recommended wearing cloth masks in public, particularly in settings in which maintaining social distancing is difficult. Therefore, cloth masks may be useful for decreasing community transmission. ${ }^{38}$

\section{CONCLUSION}

Obstetricians on busy labor and delivery units want to know how to best protect themselves from COVID19. Unfortunately, during this current COVID-19 pandemic, there has been widespread concern and confusion about personal protective equipment, particularly about types and use of masks. Although much of the focus is on facial protection, data from the SARS outbreak suggest that it is the "bundle" of 
personal protective equipment with hand hygiene and environmental cleaning that leads to decreased risk of transmission of respiratory viruses, and this is likely true for COVID-19.

The personal protective equipment guidance at the national level and at the hospital system level can be complex and confusing. Furthermore, it can change rapidly based on evolving evidence as well as availability of supplies. Although adherence to infectioncontrol procedures is important, published and anecdotal evidence suggests that health care professionals, including obstetricians, have opportunities for improvement. ${ }^{39}$ The key for obstetricians is to be familiar with whatever personal protective equipment is stocked by their labor and delivery unit, to train using that personal protective equipment, and to use personal protective equipment correctly and consistently (including donning and doffing). For places where the rapid increase of patients has not yet begun, now is a good time for labor and delivery units to conduct refresher training for personal protective equipment use and to consider conducting multidisciplinary simulations of a pregnant patient with COVID-19 infection presenting to labor and delivery. Strict adherence to hand hygiene combined with correct and consistent use of personal protective equipment and careful environmental cleaning may help reduce the risk of nosocomial transmission and help keep obstetricians healthy during this time of COVID-19.

\section{REFERENCES}

1. Rasmussen SA, Jamieson DJ. Coronavirus disease 2019 (COVID-19) and pregnancy: responding to a rapidly evolving situation. Obstet Gynecol 2020 Mar 19 [Epub ahead of print].

2. Rasmussen SA, Smulian JC, Lednicky JA, Wen TS, Jamieson DJ. Coronavirus disease 2019 (COVID-19) and pregnancy: what obstetricians need to know. Am J Obstet Gynecol 2020 Feb 24 [Epub ahead of print].

3. Verity R, Okell LC, Dorigatti I, Winskill P, Whittaker C, Imai $\mathrm{N}$, et al. Estimates of the severity of coronavirus disease 2019: a model-based analysis. Lancet Infect Dis 2020 Mar 30 [Epub ahead of print].

4. Duguid JP. The size and the duration of air-carriage of respiratory droplets and droplet-nuclei. J Hyg (Lond) 1946;44:471-9.

5. Bourouiba L. Turbulent gas clouds and respiratory pathogen emissions: potential implications for reducing transmission of COVID-19. JAMA 2020 Mar 26 [Epub ahead of print].

6. Perlman S. Another decade, another coronavirus. N Engl J Med 2020;382:760-2.

7. Ong J, Young BE, Ong S. COVID-19 in gastroenterology: a clinical perspective. Gut 2020 Mar 20 [Epub ahead of print].

8. Moser MR, Bender TR, Margolis HS, Noble GR, Kendal AP, Ritter DG. An outbreak of influenza aboard a commercial airliner. Am J Epidemiol 1979;110:1-6.

9. van Doremalen N, Bushmaker T, Morris DH, Holbrook MG, Gamble A, Williamson BN, et al. Aerosol and surface stability of SARS-CoV-2 as compared with SARS-CoV-1. N Engl J Med 2020 Mar 17 [Epub ahead of print].

10. Cheng VCC, Wong SC, Chen JHK, Yip CCY, Chuang VWM, Tsang OTY, et al. Escalating infection control response to the rapidly evolving epidemiology of the Coronavirus disease 2019 (COVID-19) due to SARS-CoV-2 in Hong Kong. Infect Control Hosp Epidemiol 2020 Mar 5 [Epub ahead of print].

11. Thompson KA, Pappachan JV, Bennett AM, Mittal H, Macken $\mathrm{S}$, Dove BK, et al. Influenza aerosols in UK hospitals during the H1N1 (2009) pandemic-the risk of aerosol generation during medical procedures. PLoS One 2013;8:e56278.

12. Tran K, Cimon K, Severn M, Pessoa-Silva CL, Conly J. Aerosol generating procedures and risk of transmission of acute respiratory infections to healthcare workers: a systematic review. PLoS One 2012;7:e35797.

13. O'Neil CA, Li J, Leavey A, Wang Y, Hink M, Wallace M, et al Characterization of aerosols generated during patient care activities. Clin Infect Dis 2017;65:1335-41.

14. Wei WE, Chiew CJ, Yong SE, Toh MP, Lee VJ. Presymptomatic transmission of SARS-CoV-2 - Singapore, January 23March 16, 2020. MMWR Morb Mortal Wkly Rep 2020;69: 411-15.

15. Kimball A, Hatfield KM, Arons M, James A, Taylor J, Spicer K, et al. Asymptomatic and presymptomatic SARS-CoV-2 infections in residents of a long-term care skilled nursing facilityKing County, Washington, March 2020. MMWR Morb Mortal Wkly Rep 2020;69:377-81.

16. Smith AC, Thomas E, Snoswell CL, Haydon H, Mehrotra A, Clemensen J, et al. Telehealth for global emergencies: implications for coronavirus disease 2019 (COVID-19). J Telemed Telecare 2020 Mar 20 [Epub ahead of print].

17. Centers for Disease Control and Prevention. Interim infection prevention and control recommendations for patients with suspected or confirmed coronavirus disease 2019 (COVID-19) in healthcare settings. Available at: https://www.cdc.gov/coronavirus/2019-ncov/hcp/infection-control-recommendations.html. Retrieved April 1, 2020.

18. Jefferson T, Del Mar CB, Dooley L, Ferroni E, Al-Ansary LA, Bawazeer GA, et al. Physical interventions to interrupt or reduce the spread of respiratory viruses. The Cochrane Database of Systematic Reviews 2011, Issue 7. Art. No.:CD006207. DOI: 10.1002/14651858.CD006207.pub4.

19. Centers for Disease Control and Prevention. Understanding the difference. Available at: https://www.cdc.gov/niosh/ npptl/pdfs/UnderstandDifferenceInfographic-508.pdf. Retrieved April 12, 2020.

20. Bischoff WE, Turner J, Russell G, Blevins M, Missaiel E, Stehle J. How well do N95 respirators protect healthcare providers against aerosolized influenza virus? Infect Control Hosp Epidemiol 2018:1-3.

21. Howard RA, Lathrop GW, Powell N. Sterile field contamination from powered air-purifying respirators (PAPRs) versus contamination from surgical masks. Am J Infect Control 2020;48:153-6.

22. Loeb M, Dafoe N, Mahony J, John M, Sarabia A, Glavin V, et al. Surgical mask vs N95 respirator for preventing influenza among health care workers: a randomized trial. JAMA 2009; 302:1865-71.

23. MacIntyre CR, Wang Q, Cauchemez S, Seale H, Dwyer DE, Yang $\mathrm{P}$, et al. A cluster randomized clinical trial comparing fittested and non-fit-tested N95 respirators to medical masks to prevent respiratory virus infection in health care workers. Influenza Other Respir Viruses 2011;5:170-9. 
24. MacIntyre CR, Wang Q, Seale H, Yang P, Shi W, Gao Z, et al. A randomized clinical trial of three options for N95 respirators and medical masks in health workers. Am J Respir Crit Care Med 2013;187:960-6.

25. MacIntyre CR, Chughtai AA, Rahman B, Peng Y, Zhang Y, Seale $\mathrm{H}$, et al. The efficacy of medical masks and respirators against respiratory infection in healthcare workers. Influenza Other Respir Viruses 2017;11:511-7.

26. Radonovich LJ Jr, Simberkoff MS, Bessesen MT, Brown AC, Cummings DAT, Gaydos CA, et al. N95 respirators vs medical masks for preventing influenza among health care personnel: a randomized clinical trial. JAMA 2019;322:824-33.

27. Ng K, Poon BH, Kiat Puar TH, Shan Quah JL, Loh WJ, Wong YJ, et al. COVID-19 and the risk to health care workers: a case report. Ann Intern Med 2020 Mar 16 [Epub ahead of print].

28. Patel A, D'Alessandro MM, Ireland KJ, Burel WG, Wencil EB, Rasmussen SA. Personal protective equipment supply chain: lessons learned from recent public health emergency responses. Health Secur 2017;15:244-52.

29. Centers for Disease Control and Prevention. Pandemic planning: recommended guidance for extended use and limited reuse of N95 filtering facepiece respirators in healthcare settings. Available at: https://www.cdc.gov/niosh/topics/hcwcontrols/ recommendedguidanceextuse.html. Retrieved April 7, 2020.

30. Rebmann T, Carrico R, Wang J. Physiologic and other effects and compliance with long-term respirator use among medical intensive care unit nurses. Am J Infect Control 2013;41:1218-23.

31. Blachere FM, Lindsley WG, McMillen CM, Beezhold DH, Fisher EM, Shaffer RE, et al. Assessment of influenza virus exposure and recovery from contaminated surgical masks and N95 respirators. J Virol Methods 2018;260:98-106.

32. Kenney P, Chan BK, Kortright K, Cintron M, Havill N, Russi M, et al. Hydrogen peroxide vapor sterilization of N95 respirators for reuse. Available at: https://www.medrxiv.org/content/10. 1101/2020.03.24.20041087v1. Retrieved April 7, 2020.

33. Centers for Disease Control and Prevention. Decontamination and reuse of filtering facepiece respirators. Available at: https:// www.cdc.gov/coronavirus/2019-ncov/hcp/ppe-strategy/ decontamination-reuse-respirators.html. Retrieved April 7, 2020.
34. Schwartz A, Stiegel M, Greeson N, Vogel A, Thomann W, Brown M, et al. Decontamination and reuse of N95 respirators with hydrogen peroxide vapor to address worldwide personal protective equipment shortages during the SARS-CoV-2 (COVID-19) pandemic. Available at: https://www.safety. duke.edu/sites/default/files/N-95_VHP-Decon-Re-Use.pdf. Retrieved April 7, 2020.

35. Lowe JJ, Paladino KD, Farke JD, Boulter K, Cawcutt K, Emodi M, et al. N95 filtering facepiece respirator ultraviolet germicidal irradiation (UVGI) process for decontamination and reuse. Available at: https://www.nebraskamed.com/sites/default/ files/documents/covid-19/n-95-decon-process.pdf. Retrieved April 7, 2020.

36. MacIntyre CR, Seale H, Dung TC, Hien NT, Nga PT, Chughtai AA, et al. A cluster randomised trial of cloth masks compared with medical masks in healthcare workers. BMJ Open 2015;5: e006577.

37. Li R, Pei S, Chen B, Song Y, Zhang T, Yang W, et al. Substantial undocumented infection facilitates the rapid dissemination of novel coronavirus (SARS-CoV2). Science 2020 Mar 16 [Epub ahead of print].

38. Centers for Disease Control and Prevention. Recommendation regarding the use of cloth face coverings, especially in areas of significant community-based transmission. Available at: https://www.cdc.gov/coronavirus/2019-ncov/prevent-gettingsick/cloth-face-cover.html. Retrieved April 7, 2020.

39. Olson CK, Iwamoto M, Perkins KM, Polen KN, Hageman J, Meaney-Delman D, et al. Preventing transmission of zika virus in labor and delivery settings through implementation of standard precautions-United States, 2016. MMWR Morb Mortal Wkly Rep 2016;65:290-2.

\section{PEER REVIEW HISTORY}

Received April 7, 2020. Received in revised form April 10, 2020. Accepted April 10, 2020. Peer reviews and author correspondence are available at http://links.lww.com/AOG/B879. 